\title{
Mesenchymal stem cells are enriched in head neck squamous cell carcinoma, correlates with tumour size and inhibit T-cell proliferation
}

F Liotta ${ }^{1,2}$, V Querci ${ }^{1}$, G Mannelli ${ }^{3}$, V Santarlasci ${ }^{1}$, L Maggi ${ }^{1}$, M Capone ${ }^{1}$, M C Rossi ${ }^{1}$, A Mazzoni ${ }^{1}$, L Cosmi $^{1,2}$, S Romagnani ${ }^{1}, \mathrm{E} \mathrm{Maggi}^{1,2}, \mathrm{O}$ Gallo $^{3}$ and F Annunziato ${ }^{*, 1,2}$

${ }^{1}$ Department of Experimental and Clinical Medicine and DENOTHE Center, University of Florence, 50134 Florence, Italy; ${ }^{2}$ Regenerative Medicine Unit and Immunology and Cellular Therapy Unit of Azienda Ospedaliero-Universitaria Careggi, 50134 Florence, Italy and ${ }^{3}$ First Clinic of Otorhinolaryngology, Head and Neck Surgery, University of Florence, Azienda Ospedaliera Universitaria Careggi, 50134 Florence, Italy

Background: Cancer is a multifactorial disease not only restricted to transformed epithelium, but also involving cells of the immune system and cells of mesenchymal origin, particularly mesenchymal stem cells (MSCs). Mesenchymal stem cells contribute to blood- and lymph- neoangiogenesis, generate myofibroblasts, with pro-invasive activity and may suppress anti-tumour immunity.

Methods: In this paper, we evaluated the presence and features of MSCs isolated from human head neck squamous cell carcinoma (HNSCC).

Results: Fresh specimens of HNSCC showed higher proportions of CD90 + cells compared with normal tissue; these cells co-expressed CD29, CD105, and CD73, but not CD31, CD45, CD133, and human epithelial antigen similarly to bone marrowderived MSCs (BM-MSCs). Adherent stromal cells isolated from tumour shared also differentiation potential with BM-MSCs, thus we named them as tumour-MSCs. Interestingly, tumour-MSCs showed a clear immunosuppressive activity on in vitro stimulated T lymphocytes, mainly mediated by indoelamine 2,3 dioxygenase activity, like BM-MSCs. To evaluate their possible role in tumour growth in vivo, we correlated tumour-MSC proportions with neoplasm size. Tumour-MSCs frequency directly correlated with tumour volume and inversely with the frequency of tumour-infiltrating leukocytes.

Conclusions: These data support the concept that tumour-MSCs may favour tumour growth not only through their effect on stromal development, but also by inhibiting the anti-tumour immune response.

It is well established that cancer is not simply a disease confined to transformed epithelial cells, but it is deeply influenced by the stromal microenvironment. In this context, immune cells (Finn, 2012) and cells of mesenchymal origin (Bergfeld and DeClerck, 2010) have a major role.

Cells derived by the mesenchymal lineage are responsible for stromal architecture, blood- and lymph-vessel formation and for the production of several soluble and surface molecules, including growth factors, chemokines, and molecules with immunosuppressive activity. In this context, mesenchymal stem cells (MSCs), are thought to have a pivotal role (Rajantie et al, 2004; Mishra et al, 2008; Spaeth et al, 2009).

MSCs are adherent, multipotent, non-hematopoietic progenitor cells, initially obtained and characterised from bone marrow (BM)

*Correspondence: Professor F Annunziato; E-mail: francesco.annunziato@unifi.it

Received 6 August 2014; revised 19 November 2014; accepted 22 December 2014; published online 3 February 2015 
samples, which have multilineage differentiation potential into various tissues of different origin, including adipocytes, osteoblasts, chondrocytes, tenocytes, skeletal and cardiac myocytes, cells of visceral mesoderm, and neural cells (Nakahara et al, 1991; Natsu et al, 2004; Horwitz et al, 2005; Rojas et al, 2005; Gucciardo et al, 2009). MSCs can be obtained from tissues other than BM, such as fat (Zuk et al, 2002), periodontal ligament (Mitrano et al, 2010), glomeruli (Bruno et al, 2009), placenta (In't Anker et al, 2003), endometrium (Schüring et al, 2011), umbilical cord blood (Bieback and Kluter, 2007), fetal BM, blood, lung, liver, spleen, and peripheral blood (PB) (Flynn et al, 2007). As there are no specific markers for human MSCs, they are recognised on the basis of a complex immunophenotype, including the lack of hematopoietic stem cell (i.e., CD45 and CD34) and endothelial cell (i.e., CD31) markers, and the expression of a number of surface molecules, such as CD105, CD73, CD106, CD54, CD44, CD90, CD29, and STRO-1 (Horwitz et al, 2005). However, the MSC nature of adherent stromal-like cells can be confirmed only with functional assays that show their capacity to undergo multilineage differentiation in vitro under the effect of specific media (Horwitz et al, 2005).

One of the solid tumours in which a potential negative role of MSCs has been proposed is the head neck squamous cell carcinoma (HNSCC) (De Boeck et al, 2010). In particular, an increasing body of data support the hypothesis that resident and/or bone marrow-derived MSCs are the precursors of the stromal cell populations present in solid tumours (Lin et al, 2007; Sun et al, 2011; Xu et al, 2011; Hu et al, 2013). Here these cells contribute to blood and lymph neoangiogenesis, and generate tumour-associated myofibroblasts, known to possess pro-invasive activity (De Wever et al, 2008; De Boeck et al, 2010). More importantly some researchers, starting from previous data demonstrating the immunosuppressive activity of MSCs (Bartholomew et al, 2002; Le Blanc et al, 2004; Krampera et al, 2006; Liotta et al, 2008; Baron et al, 2010), have proposed that tumour-associated MSC could modulate the anti-tumour response of the immune system, favouring tumour growth (De Wever et al, 2008).

Head neck squamous cell carcinoma is the sixth leading cancer by incidence worldwide, there are about 780000 new cases per year all over the world and only $40 \%-50 \%$ of patients with HNSCC will survive for 5 years (Forastiere et al, 2001). The incidence of this tumour depends on several factors, including geographic arrangement, indeed, HNSCC reaches the $50 \%$ of all of the tumours in East Asia, vs 5\% in Europe and America. Tobacco use is the principle cause of malignant HNSCC: the risk of developing the tumour in smokers is three to four times higher than in nonsmokers. The alcohol intake is the second risk factor. Furthermore, a subgroup of HNSCCs, particularly those of the oropharynx, seems to be associated with infection with high-risk types of human papillomavirus (HPV). Human papillomavirus-positive and HPV-negative tumours represent different clinicalpathological and molecular entities (Sturgis and Cinciripini, 2007). Despite advances in treatment, which have improved the quality of life, survival rates are not improved significantly in the last 30 years. Mortality remains high because of the development of lymph node and distant metastases, the emergence of therapy resistance, the occurrence of local and regional recurrences. One clear indication on the contribution of the immune system in controlling HNSCC is the relative increase of tumour incidence in the presence of acquired or iatrogenic immunodeficiency. King et al (1995). identified premalignant lip leukoplakia in $13 \%$ of renal transplant patients, as compared with $0.6 \%$ of control age- and sexmatched individuals. Of these patients, a majority demonstrated dysplastic conversion and $10 \%$ of them showed the presence of HNSCC. Many other reports examining databases of transplant recipients confirmed this increased prevalence of tumour (Harris and Penn, 1981). In addition, analysis of patients who underwent bone marrow transplantation for haematologic malignancies also demonstrated a 17.4-fold increased risk for oral cancer (Baker et al, 2003).

In the present study, we aimed to assess the presence of MSCs in HNSCC and to evaluate their biologic role with particular regard to the immune response. As first step, we studied, by flow cytometry, the cell composition of single-cell suspensions derived from fresh tumour tissue samples: epithelial elements (HEA + cells), cells of stromal origin $(\mathrm{CD} 90+$ cells $)$, endothelial cells $(\mathrm{CD} 31+$ cells $)$ and leukocytes (CD45 + cells). Subsequently, we isolated mesenchymal stromal cells, by selecting adherent cells from in vitro culture in plastic flasks, accordingly with the recommendations of the International Society for Cellular Therapy 2005 for the isolation of MSCs. These cell cultures resulted homogenous for cell composition in terms of morphology (fibroblast-like shape) and were absolutely comparable to bone marrow-derived MSCs (BMMSCs) in terms of cell phenotype and differentiation potential, so we will refer to these cells as tumour-derived MSCs (tumourMSCs). Moreover, we found that tumour-MSC were able to abrogate $\mathrm{T}$-cell proliferation in a dose-dependent fashion, mainly through IDO activity comparably with conventional BM-MSC. Finally, to evaluate the possible negative in vivo role of tumourMSCs, we correlated their frequencies in HNSCC specimens, with tumour dimension and we observed a direct correlation.

\section{MATERIALS AND METHODS}

Subjects. Thirteen patients affected by HNSCC, biopsy proven, were prospectively enrolled in this study between December 2010 and May 2012 with the assent of the Florence University Hospital. All the participants signed an informed consent agreement and the procedures followed in the study were approved by the AOUC (Azienda Ospedaliero-Universitaria Careggi) Ethical Committee. The sites and stage of the tumour have been classified according to the AJCC TNM (Edge et al, 2010). Primary tumour volume was calculated on the basis of diagnostic imaging, as it is represented by computer-assisted tomography three-dimensional prospective.

Tumoral and normal tissue specimens were obtained in general anaesthesia during surgical procedure, under sterile conditions; peripheral blood samples were taken when patients arrived in the operating room. Inclusion criteria for enrolment of patients in the following study were: (1) biopsy-proven HNSCC patients, (2) patients affected by primary head and neck tumours previously untreated, (3) patients with no tumour medical history, (4) absence of systemic metastasis. The patients description is summarised in Table 1.

Outpatient follow-up included clinical examination monthly during the first year after surgery and every 2 months during the second year after surgery. A control by computer-assisted tomography (CAT) was obtained at 1 month postoperatively and twice a year postoperatively and/or after radiotherapy complementary treatment, in accordance with recommendations made by the ethical standards of the Regional Committee on Human Experimentation.

Reagents. The medium used for T-cell culture was RPMI 1640 (Seromed, Berlin, Germany), supplemented with $2 \mathrm{~mm}$ L-glutamine, $1 \%$ nonessential amino acids, $1 \%$ sodium pyruvate, $2 \times 10^{-5} \mathrm{M}$ 2-mercaptoethanol (all from Invitrogen, Life Technology, Thermofischer Scientific Inc, Lafayette, CO, USA) and 10\% FBS HyClone (Gibco Laboratories, Grand Island, NY, USA). Fluorochrome-conjugated anti-CD90, CD31, CD45, CD44, CD73, CD3, CD45, CD14, CD34, and human epithelial antigen (HEA) were purchased from BD Biosciences (San Diego, CA, USA). Anti-CD29 and anti-CD105 were obtained from Ancell Corporation, Bayport, MN, USA. Oil Red O, Alizarin Red S, insulin, IBMX (3-isobutil1-metilxantina), indomethacin, dexamethasone were purchased from Sigma Aldrich, St. Louis, MO, USA. 
Table 1. Patients characteristics

\begin{tabular}{|c|c|c|c|c|c|c|c|}
\hline Patients & Gender & $\begin{array}{c}\text { Age } \\
\text { (years) }\end{array}$ & $\begin{array}{l}\text { Site of } \\
\text { tumour }\end{array}$ & $\begin{array}{l}\text { TNM } \\
\text { status }\end{array}$ & $\begin{array}{c}\text { Tumour } \\
\text { volume (cc) }\end{array}$ & $\begin{array}{l}\text { Previous } \\
\text { radiotherapy- } \\
\text { chemotherapy }\end{array}$ & $\begin{array}{l}\text { Follow-up } \\
\text { (months) }\end{array}$ \\
\hline$\# 1$ & $\mathrm{~F}$ & 51 & Larynx & pT3NOMO & 12.74 & No & 25 \\
\hline \#2 & $\mathrm{M}$ & 64 & Tongue & pT1N0M0 & 0.8736 & No & 25 \\
\hline$\# 3$ & $M$ & 66 & Larynx & pT3N2cM0 & 4.94 & No & 25 \\
\hline$\# 4$ & $M$ & 71 & Larynx & pT1N1aM0 & 0.52 & No & 24 \\
\hline$\# 5$ & $\mathrm{~F}$ & 65 & Oral cavity floor & pT4bN1M0 & 1.04 & No & 23 \\
\hline \#6 & $M$ & 76 & Oral cavity floor & T4bNOMO & 22.23 & No & 21 \\
\hline$\# 7$ & $M$ & 64 & Larynx & pT2NOMO & 0.0364 & No & 21 \\
\hline$\# 8$ & $M$ & 57 & Tonsil & pT3N2cM0 & 15.6 & No & 20 \\
\hline$\# 9$ & M & 47 & Tongue & pT2NOMO & 6.864 & No & 15 \\
\hline$\# 10$ & $\mathrm{~F}$ & 66 & Tonsil & pT2N2cMO & 1.95 & No & 13 \\
\hline$\# 11$ & $\mathrm{~F}$ & 66 & Larynx & pT2N1M0 & 0.39 & No & 8 \\
\hline$\# 12$ & $\mathrm{~F}$ & 65 & Larynx & pT3N1M0 & 0.676 & No & 10 \\
\hline \multirow[t]{2}{*}{$\# 13$} & $M$ & 60 & Larynx & pT4aN2bM0 & 2.184 & No & 9 \\
\hline & $8 \mathrm{M} / 5 \mathrm{~F}$ & $62.8 \pm 7.8$ s.d. & & & & & $18.4 \pm 6.5$ s.d \\
\hline
\end{tabular}

Generation of MSCs from BM. Mesenchymal stem cells were generated from $\mathrm{BM}$ aspirates of three healthy donors, recruited after informed consent, following the procedures of the International Society for Cellular Therapy 2005 (Dominici et al, 2006). Bone marrow mononuclear cells were separated by density gradient centrifugation (Lymphoprep; Nycomed, Oslo, Norway) and cultured in $25-\mathrm{cm}^{2}$ flask (BD Biosciences) at a concentration of $30 \times 10^{6}$ nucleated cells in $5 \mathrm{ml}$ of Dulbecco's modified Eagle's medium, GlutaMax I, 10\% heat-inactivated adult bovine serum, penicillin $\left(100 \mathrm{U} \mathrm{ml}^{-1}\right)$, and streptomycin $\left(100 \mu \mathrm{g} \mathrm{ml}^{-1}\right)$. Cultures were incubated at $37{ }^{\circ} \mathrm{C}$ in a $5 \% \mathrm{CO}_{2}$ atmosphere. After $72 \mathrm{~h}$, nonadherent cells were removed. When $70 \%-80 \%$ adherent cells were confluent, they were trypsinised $\left(0.25 \mathrm{mg} \mathrm{ml}^{-1}\right.$ at $37^{\circ} \mathrm{C}$ for $\left.5 \mathrm{~min}\right)$, harvested, and expanded in larger flasks. Out of cells that were expanded for at least 3 weeks, $>99 \%$ of them displaying a homogeneous immunophenotypic pattern were used for the experiments.

Generation of MSCs from HNSSC. To obtain single-cell suspensions, tumour fragments were first gently digested with collagenase IV (500 $\mathrm{U} \mathrm{ml}^{-1}$, Sigma Aldrich) and then passed through a stainless-steel mesh (Medimachine; Becton Dickinson, San Diego, CA, USA). After these procedures, cell suspensions were cultured as reported in the previous paragraph.

Flow cytometric analysis. Tumour-ASCs immunophenotypic analysis was performed as detailed elsewhere (Krampera et al, 2006). Briefly, tumour-MSCs were detached using EDTA-buffer, washed, and resuspended at $10^{6}$ cells per millilitre. One hundred microlitres of cell suspension was incubated with the specific mAbs at $+4{ }^{\circ} \mathrm{C}$ for $30 \mathrm{~min}$; cells were then washed and analysed on a BDLSRII flow cytometer using the Diva software (BD Biosciences).

Tumour-MSCs and BM-MSCs differentiation assay. The differentiation potential of tumour-MSCs and BM-MSCs was assessed by testing their ability to differentiate into adypocytes and osteoblasts. Adipocytic differentiation was achieved after a 3-week culture of MSCs in adipogenic medium composed of DMEM with high glucose, $10 \%$ bovine serum, $1 \mu \mathrm{M}$ dexamethasone, $0.5 \mu \mathrm{M}$ 3-isobutyl-1-methylaxantine, $10 \mu \mathrm{g} \mathrm{ml}^{-1}$ insulin, and $100 \mu \mathrm{m}$ indomethacin. After 3 weeks, the culture medium was removed from all cultures and cells were smoothly washed with $2 \mathrm{ml}$ of PBS to not affect the cell monolayer, PBS was then removed and $2 \mathrm{ml}$ of $10 \%$ formaldehyde were added for $30 \mathrm{~min}$ at room temperature. Subsequently, formaldehyde was removed from each well, cells washed with water, and $2 \mathrm{ml}$ of $60 \%$ isopropanol were added for 2-5 min. Then isopropanol was removed and the cells were stained with $2 \mathrm{ml}$ of Oil Red O (reconstituted in 99\% isopropanol) for $5 \mathrm{~min}$. After several washes with warm tap water, cells were counterstained with haematoxylin for $1 \mathrm{~min}$, rinsed with tap water and visualised on a phase contrast microscope. Osteoblastic differentiation was achieved after a 3-week culture with osteoblastic medium containing DMEM high glucose, $2 \%$ bovine serum, $10^{-7} \mathrm{M}$ dexamethasone, $50 \mu \mathrm{g} \mathrm{ml}^{-1}$ ascorbic acid, and $10 \mathrm{~mm}$ $\beta$-glycerophosphate. The cells were then washed with PBS, fixed with $10 \%$ formaldehyde for $10 \mathrm{~min}$, rinsed with PBS, stained with Alizarin Red ( $1 \mathrm{mg} \mathrm{ml}^{-1}$, dissolved in distilled water) for $3 \mathrm{~min}$, washed few times with tap water and analysed on a phase contrast microscope. Also specific markers of adipoblasts and osteoblasts were analysed by real-time quantitative RT-PCR at different time points during cell differentiation.

Isolation of $\mathrm{CD} 4+$ or $\mathrm{CD} 8+\mathrm{T}$ Cells from $\mathrm{PB}$. Negative selection of $\mathrm{CD} 4+$ or CD8 $+\mathrm{T}$ cells from $\mathrm{PB}$ of healthy donor was performed by MACS (Miltenyi Biotec, Bisley, UK; DE, EU), as described elsewhere (Krampera et al, 2006). The purity of the negatively selected populations was consistently $\geqslant 97 \%$.

Proliferation assays. Purified CD $4+$ or CD $8+$ human $\mathrm{T}$ cells $\left(10^{5}\right.$ cells) were stimulated with either $10^{5}$ irradiated $(9000 \mathrm{rad})$ allogeneic T-cell-depleted PBMCs (MLR - mixed lymphocytes reaction) plus $1 \mu \mathrm{g} \mathrm{ml}^{-1}$ of anti-CD3 $\mathrm{mAb}$ (BD Biosciences); or $5 \mu \mathrm{g} \mathrm{ml}^{-1}$ anti-CD3 plus $5 \mu \mathrm{g} \mathrm{ml}^{-1}$ anti-CD28 $\mathrm{mAb}$ (BD Biosciences), in the absence or presence of different numbers of tumour-MSCs $\left(2 \times 10^{4}, 10^{4}, 10^{3}, 10^{2}\right.$ per well). Co-culture experiments were performed in RPMI 1640 medium (Seromed), supplemented as indicated in the first paragraph. On day 5 , cultures were pulsed for $8 \mathrm{~h}$ with $0.5 \mu \mathrm{Ci}(0.0185 \mathrm{MBq})$ of ${ }^{3} \mathrm{H}-\mathrm{TdR}$ (Amersham, Little Chalfont, UK) harvested, and radionuclide uptake was measured by scintillation counting. Some experiments were conducted in the presence of the IDO1 inhibitor 1-methyl-L-tryptophan $(1,0.5$, or $0.25 \mathrm{~mm}$ ) or in the presence of the COX inhibitor indomethacin $(1,0.5,0.25 \mathrm{mcm})$ purchased from Sigma Aldrich.

Cytokine production assay. Anti-CD3 plus anti-CD28-stimulated $\mathrm{CD} 4+$ or $\mathrm{CD} 8+\mathrm{T}$ cells were co-cultured in the presence or in the absence of MSCs as described above, culture supernatants were collected after $72 \mathrm{~h}$ to evaluate TNF- $\alpha$ and IFN- $\gamma$ production. The amounts of cytokines were measured by a commercial ELISA kit (R\&D System) according to the manufacturer's instructions. 
Chemotactic assay. BM-MSC or tumour-MSC were stimulated in the presence of recombinant TNF- $\alpha$ plus IFN- $\gamma\left(10 \mathrm{ng} \mathrm{ml}^{-1}\right.$ and $2 \mathrm{ng} \mathrm{ml}^{-1}$, respectively) to induce chemokines production. After $24 \mathrm{~h}$, culture medium was removed and fresh medium (RPMI 1640) was added for further $24 \mathrm{~h}$. The culture supernatants were then collected and added to the bottom well of a transwell chamber ( $5 \mu \mathrm{m}$ pore size, 24 wells; Costar, Corning Incorporated, Corning, NY, USA). Freshly isolated $2.5 \times 10^{5} \mathrm{CD} 4+$ or $\mathrm{CD} 8+\mathrm{T}$ cells, obtained from peripheral blood of healthy donors, were resuspended in normal culture medium and loaded into the top well. Cell migration was allowed to occur for $4 \mathrm{~h}$ at $37^{\circ} \mathrm{C}$ and cells migrating to the lower chamber were collected and counted by $\mathrm{BD}$-LSR cytofluorimeter. Cells that migrated in the presence of medium alone served as a negative control, whereas those migrating in the presence of CXCL10 $\left(200 \mathrm{ng} \mathrm{ml}^{-1}\right)$ served as positive control.

Real-time quantitative RT-PCR. Taq-Man RT-PCR was performed, as described elsewhere (Cosmi et al, 2008; Annunziato and Romagnani, 2010; Murphy and Stockinger, 2010). Primers and probes used were from Applied Biosystems (Foster City, CA, USA).

Statistical analysis. An unpaired samples $t$-test was used to assess the difference of MSCs frequency between tumour and healthy tissue (Figure 1), between mRNA expression of adipocytes or osteoblasts cell markers in undifferentiated and in vitro differentiated tumour-MSCs (Figure 3) and between cell proliferation of polyclonally stimulated $\mathrm{T}$ cells in the absence or in the presence of tumour-MSCs (or BM-MSCs as control condition, Figure 4, panel A and B). The correlation between the frequency of CD90-positive cells and tumour volume, and between CD90-positive cells and CD45 + or CD31 + cells was evaluated on the basis of $R^{2}$ and number of subjects (Figure 5). $P<0.05$ (two-tailed) was considered statistically significant.

\section{RESULTS}

CD90-positive stromal cells are enriched in HNSCC. As first step, we evaluated the relative proportions of cells belonging to different cell lineages in HNSCC or healthy tissue derived from the upper aerodigestive tract. In particular, we generated single-cell suspensions from specimens derived from 13 different HNSCCaffected patients. From 6 out of the 13 patients, it was possible to obtain also control specimens (healthy tissue) derived from the contralateral of the tumour. Cell suspensions were evaluated by flow cytometry to establish the frequency of epithelial elements (HEA + cells), of stromal cells (CD90 + cells), of endothelial cells (CD31 + cells), and of leukocytes (CD45 + cells). Debris and dead cells were excluded from the plot analysis on the basis of physic parameters, as well as the propidium iodide uptake method. CD31, together with CD29, CD105, CD73, and CD133 have been evaluated on eight patients out of 13 , depending on the number of cells recovered from tumoral specimens.

As shown in Figure 1A, the frequency of CD90 + cells were significantly higher in tumour $v s$ control specimens. Even if frequencies of HEA and CD31 expressing cells were slightly higher in tumoral specimens as compared with healthy tissues, the differences were not statistically significant. The unexpected low frequency of HEA-positive cells in the tumoral specimens was related to the high frequency of propidium iodide-positive cells among them (data not shown).

Adherent stromal cells obtained in vitro from HNSCC share phenotypic and stemness properties with BM-MSCs from healthy subjects. We obtained, from 9 out of the 13 patients, a number of cells that allowed their seeding in plastic flasks, to derive stromal adherent cells accordingly to the procedures recommended by the International Society for Cellular Therapy (2005) for the

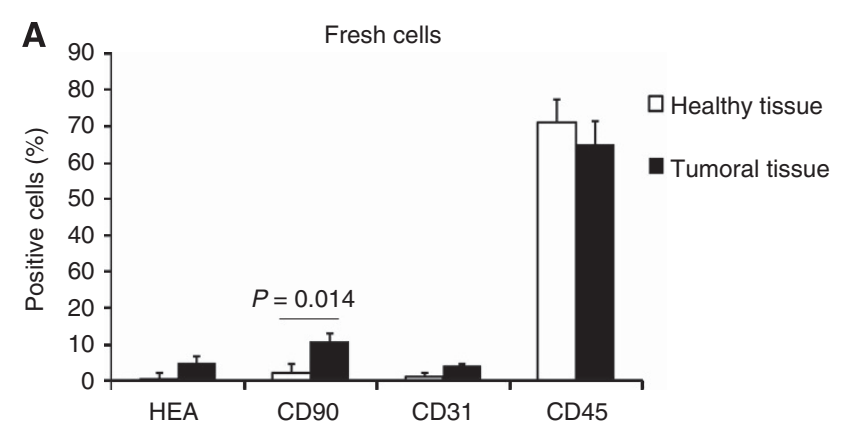

B

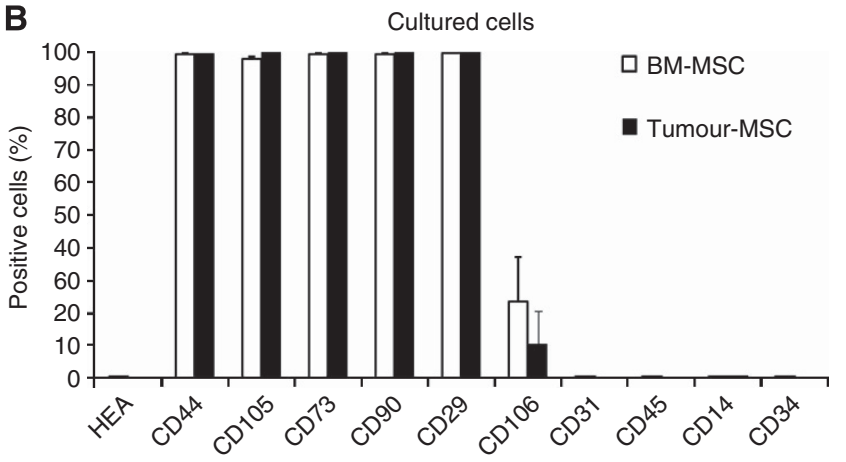

Figure 1. CD90 + cells are enriched in HNSCC. (A) The relative proportions of HEA +, CD90 +, CD31+, and CD45 + cells were assessed by flow cytometry on fresh single-cell suspensions derived from HNSCC specimens (black columns, $n=13$ for HEA, CD90, and CD45; $n=8$ for CD31), or control healthy tissue (white columns, $n=6$ ). Columns represent mean values \pm s.e. of independent experiments. $P$-value is calculated comparing tumoral tissue vs healthy tissue. (B) Tumour-derived stromal cells and control BM-MSCs share the same immunophenotype. Adherent homogeneous stromal cells obtained from seven different patients were collected at list after 3 weeks of culture and assessed by flow cytometry for MSCs markers (black columns), and compared with control BM-MSCs obtained from three different healthy donors (white columns). Columns represent mean values \pm s.e.

isolation of MSCs. Two cell cultures out of nine were discarded because of bacterial contamination; the remaining seven cultures proliferated in vitro as homogeneous adherent cells populations resembling the morphology of BM-MSCs. After 3 weeks of culture (p3-p4), cells were detached, collected, and evaluated by flow cytometry for the expression of conventionally accepted BM-MSC cell markers, namely CD44, CD105, CD73, CD90, CD29, CD31, CD45, CD14, CD34. Moreover, to exclude the presence of epithelial cells, we assessed these cells also for human epithelial antigen (HEA) positivity, in as much as the starting cell suspensions contained also epithelial elements. As shown in Figure 1B, adherent stromal cells obtained from tumour specimens shared the same phenotype with control BM-MSCs (obtained from three different healthy donors). To further exclude the presence of epithelial elements, we evaluated by real-time quantitative RTPCR, all cell cultures for the expression of mRNA for cytokeratin, and we could confirm the absence of this marker (data not shown).

To study the differentiation potential of tumour-adherent stromal cells towards osteogenic or lipogenic lineages, we cultured the cells from the six cultures possessing sufficient numbers of elements, in the presence of appropriate culture media. In particular, tumour-adherent stromal cells or BM-MSCs, used as standard control, were seeded in the presence of adipogenic, osteogenic, or normal culture medium. After 3 weeks, adherent cells from the above-mentioned culture conditions were stained with Oil Red $\mathrm{O}$ to evaluate lipogenic differentiation, or with 
Alizarin Red, to evaluate osteogenic differentiation. As represented in Figure 2A, neither BM-MSC, nor tumour-adherent stromal cells, acquired any positive staining when cultured in normal culture medium, whereas both kinds of cells were positively stained with Oil Red O, when cultured in lipogenic medium, or with Alizarin Red when conditioned by osteogenic medium. To further support these data, mRNAs for markers highly expressed during adipoblast or osteoblast differentiation were measured at different time points of cell culture by real-time quantitative RT-PCR. With regard to adipoblast differentiation, tumour-adherent stromal cells acquired a clear mRNA expression for PPAR- $\gamma$ and for FABp4, similar to that of BM-MSC (Figure 2 panel B). Moreover, when these cells were cultured in the presence of osteogenic medium, they acquired a significant upregulation of the mRNAs for the osteoblast's markers alkaline phosphatase (ALP), Runt-related transcription factor 2 (RUNX 2) and osteocalcin (Figure 2 panel C). On the basis of these results, we named the adherent stromal cells derived from HNSCC as tumour-MSCs, in analogy to BM-MSCs.

Tumour-MSCs inhibit in vitro cell proliferation and cytokine production of activated $\mathrm{CD} 4+$ and $\mathrm{CD} 8+\mathrm{T}$ cells. It is well established that BM-MSCs display immunosuppressive activity towards various immune system cell types and in particular vs $\mathrm{T}$ cells. We, therefore, wondered if tumour-MSCs, resembling BM-MSC for phenotypic features and differentiation potential, also displayed immunoregulatory properties. To assess this point, we co-cultured polyclonally- (anti-CD3 plus anti-CD28) or MLR-stimulated allogeneic CD4 + or CD8 + T cells with scalar
A
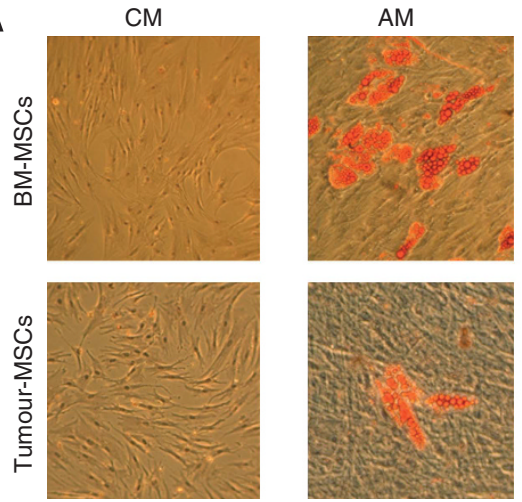

B

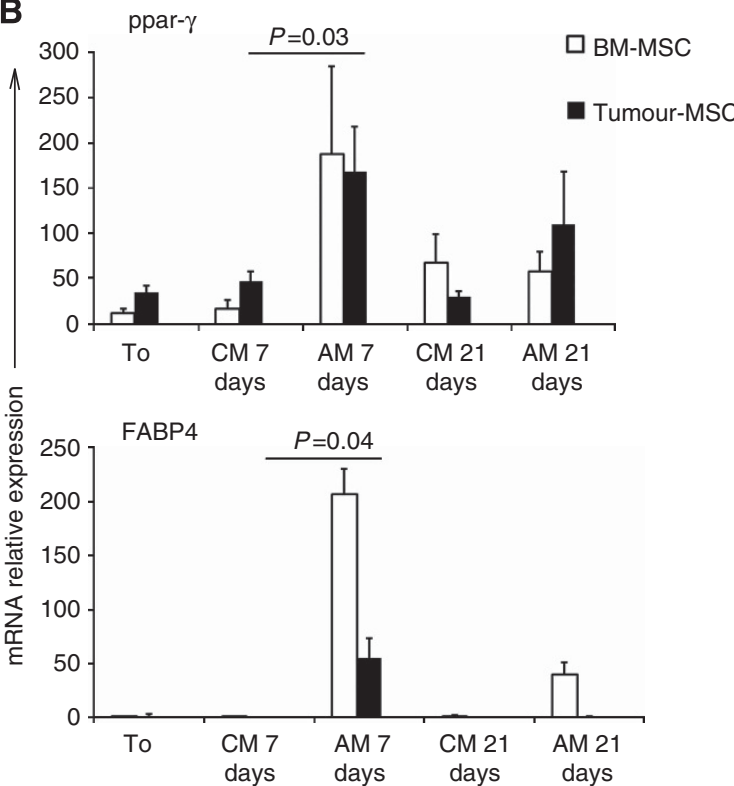

$\mathrm{OM}$
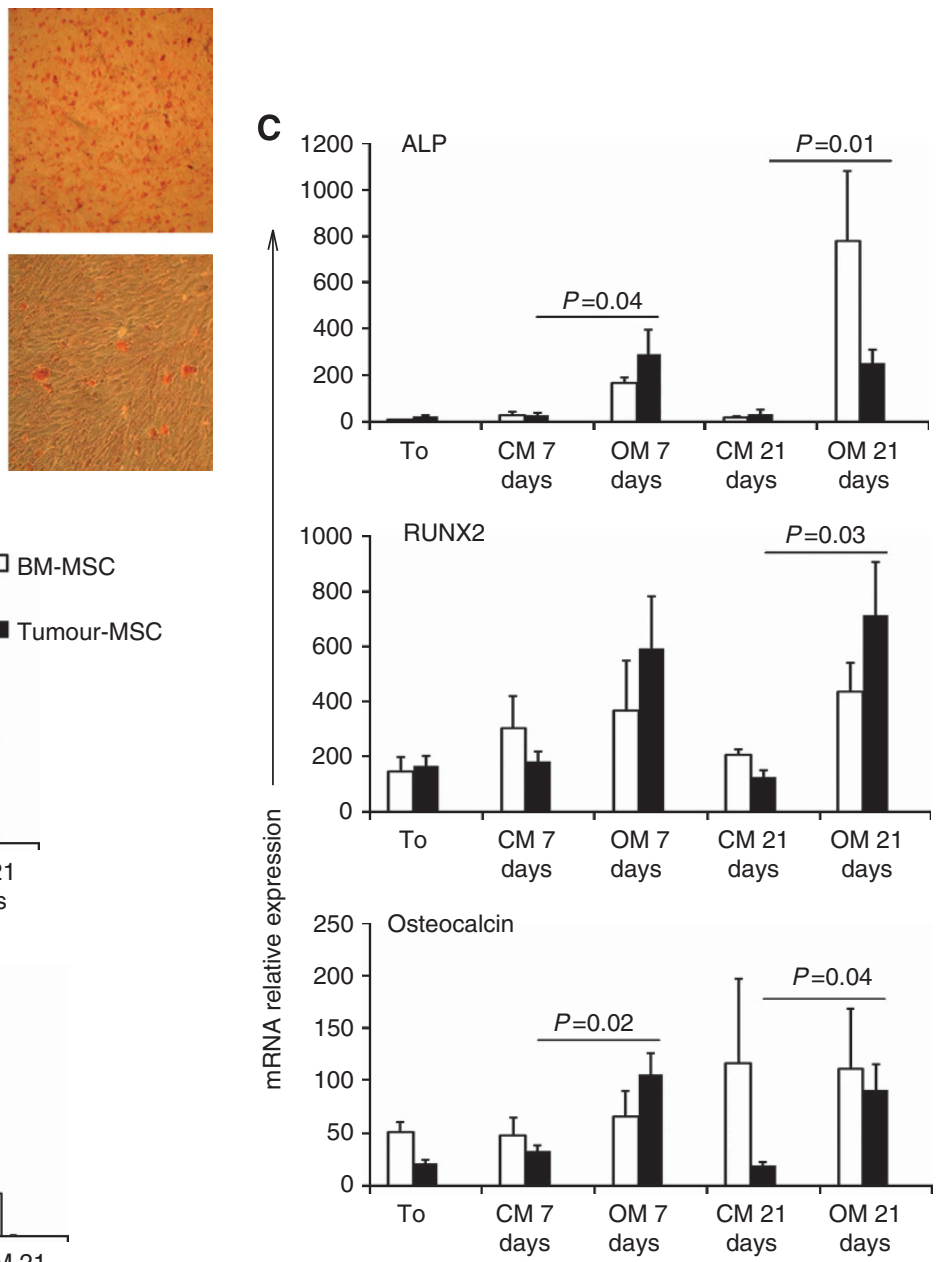

Figure 2. Adherent stromal cells derived from tumours specimens acquires typical adipoblast or osteoblast staining after adequate in vitro conditioning. (A) Adherent cells derived from HNSCC specimens of six different patients or control BM-MSCs, were cultured in normal culture medium (CM), in the presence of osteogenic medium (OM) or adipogenic medium (AM) for 21 days. After this period, tumour-derived stromal cells were stained with haematoxylin and eosin plus Oil Red O or with Alizarin Red, and compared with BM-MSCs to assess their in vitro cell differentiation. Phase contrast images were obtained by an optic microscope (Axiovert $40 \mathrm{C}$ Carl Zeiss) with a $\times 20$ magnification. A representative case out of six is reported (tumour-MSCs) and compared with a representative control case out of three (BM-MSCs). (B, C) Adherent stromal cells derived from HNSCC specimens acquires typical adipoblast or osteoblast mRNAs after in vitro culture in the presence of appropriate conditioning medium. mRNA levels for adipoblast or osteoblast markers were evaluated in HNSCC-derived adherent stromal cells (black columns, $n=6)$ or in BM-MSCs (white columns, $n=3$ ) at the beginning of the experiment (time $0-T 0$ ), after 7 and 21 days of culture in the presence of normal culture medium (CM), adipogenic medium (AM), or osteogenic medium (OM). B reports mean values \pm s.e. of the specific mRNAs for the adipose markers ppar- $\gamma$ and FABp4 at the different time points. C reports the mRNAs mean values \pm s.e. for the osteogenic markers alkaline phosphatase (ALP), Runt-related transcription factor 2 (RUNX 2) and osteocalcin. P-values are evaluated for HNSCC-derived adherent stromal cells vs own control condition (CM) at each time point. 

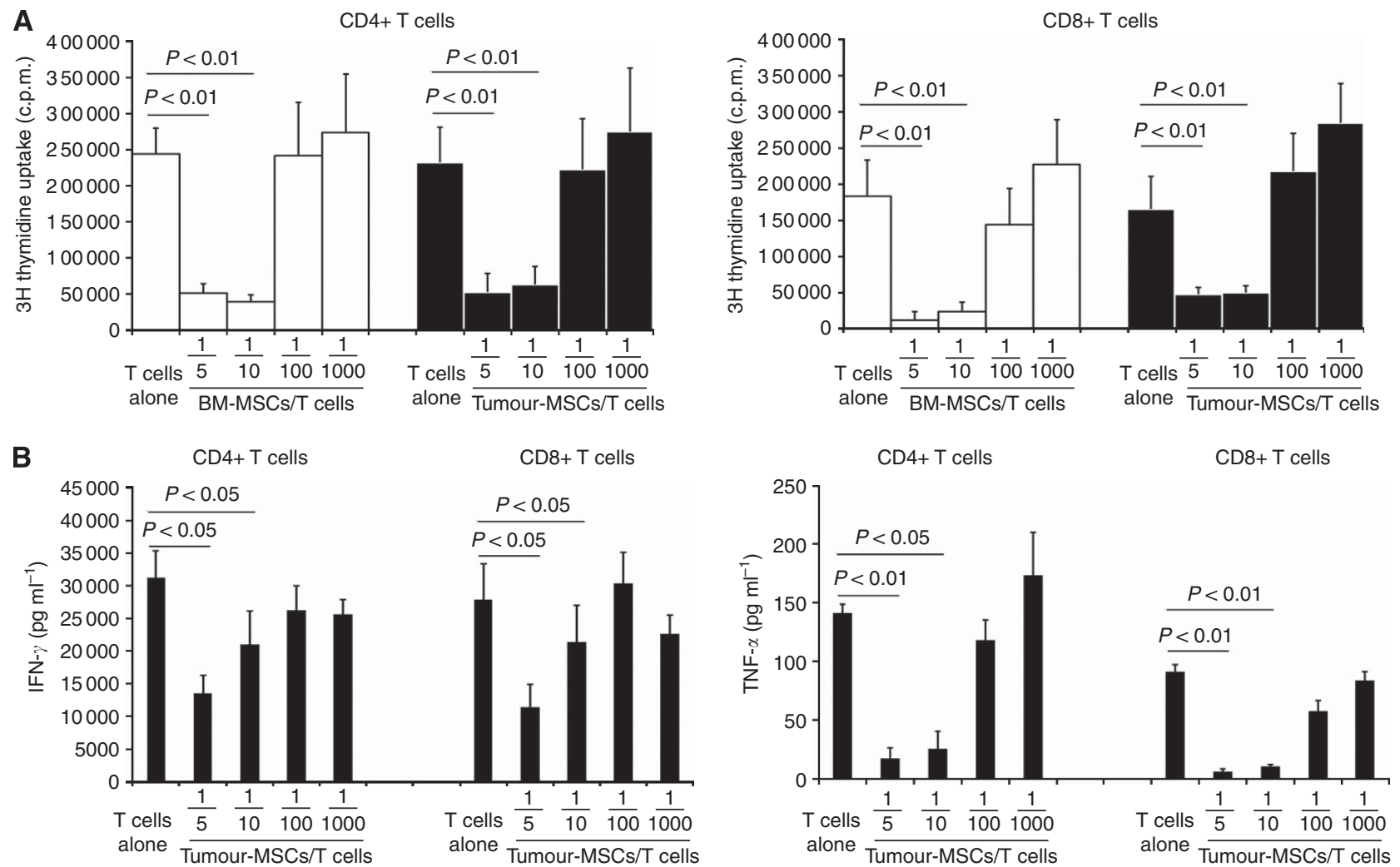

Figure 3. Tumour-MSCs inhibit in vitro cell proliferation and cytokines production by polyclonally stimulated CD4 + and CD8 + T lymphocytes. (A) Proliferation of polyclonally stimulated (anti-CD3 plus anti-CD28) T lymphocytes was assessed after 5 days of culture on the basis of 3H thymidine incorporation in the absence (T) or in the presence of tumour-MSCs (black columns) or of BM-MSCs (white columns) as control condition. Histograms represent mean values \pm s.e. of six different experiments. P-values are evaluated vs T cells alone. (B) Cytokine production by polyclonally stimulated T lymphocytes was assessed in supernatants by ELISA, after 3 days of culture in the absence (T) or in the presence of tumour-MSCs. Histograms represent mean values \pm s.e. of three different experiments. $P$-values are evaluated vs $T$ cells alone.

numbers of tumour-MSCs or of BM-MSCs (control cells); both adherent cells types were seeded in the absence or presence of stimulated $\mathrm{T}$ cells at different MSC/T cells ratios: $1 / 5,1 / 10,1 / 100$, and $1 / 1000$. On day 5 , lymphocytes were assessed for their ability to proliferate through the evaluation of $3 \mathrm{H}-\mathrm{TdR}$ uptake. As shown in Figure 3A, the addition in cultures of tumour-MSCs significantly inhibited the proliferation of stimulated $\mathrm{T}$ cells in a dosedependent fashion. Of note, the immunosuppressive behaviour of tumour-MSC was comparable to the one of BM-MSCs.

$\mathrm{T}$ cells were also evaluated for cytokine production, in particular, anti-CD3 plus anti-CD28-stimulated $\mathrm{CD} 4+$ or $\mathrm{CD} 8+\mathrm{T}$ cells were co-cultured in the presence or in the absence of MSCs as described above, culture supernatants were collected after $72 \mathrm{~h}$ to evaluate TNF- $\alpha$ and IFN- $\gamma$ production. As shown in Figure $3 \mathrm{~B}$, the production of both cytokines was significantly inhibited by tumour-MSCs in CD4 + and $\mathrm{CD} 8+\mathrm{T}$ cells, particularly at the higher MSC/T-cell ratio.

Tumour-MSC inhibits T-cell proliferation via indoelamine 2,3 dioxygenase (IDO) activity. To define the molecular mechanism at the base of tumour-MSCs immunoregulation, we took advantage of our previous data regarding the role of the enzyme IDO1 in the immunoregulatory activity of human BM-MSCs (Krampera et al, 2006) In particular, we repeated the above-mentioned experiments on the basis of MSC/T-cell co-cultures, in the presence or absence of the IDO1 inhibitor methyl-L-tryptophan. As shown in Figure 4A, this compound significantly abrogated the immunoregulatory activity of tumour-MSCs, in a dose-dependent fashion, demonstrating the role of IDO in the molecular mechanism of immunoregulation of tumour-MSCs. To define the possible involvement of PGE2, which has been previously shown to have a role in the inhibitory activity of BM-MSC (Le Blanc et al, 2004), in the immunosuppressive feature of tumour-MSC, we performed experiments on the basis of MSC/T-cell co-cultures, in the presence or absence of the COX inhibitor indomethacin which impairs PGE2 production. The results showed that blocking of PGE2 production in tumour-MSC was not able to restore CD4+ $\mathrm{T}$-cell proliferation (Figure $4 \mathrm{~B}$ ).

Tumour-MSC exert chemotactic activity on $\mathbf{T}$ cells. Although the above-described immunosuppressive mechanism is not contact dependent, it requires that MSCs and T cells share the same microenvironment. In a previous study (Krampera et al, 2006), we found that on stimulation with the inflammatory cytokines IFN- $\gamma$ and TNF- $\alpha$, BM-MSC produce CXCL10, a chemokine highly active on T cells. In the present study, we found that tumour-MSC also are able to produce CXCL10 under the same experimental conditions (data not shown). To demonstrate that tumour-MSC can actively attract $\mathrm{T}$ cells, a transwell chemotactic assay was performed, in which $\mathrm{CD} 4+$ or $\mathrm{CD} 8+\mathrm{T}$ cells were induced to migrate in response to supernatants obtained from two stimulated tumour-MSC. As shown in Figure 5, not only recombinant CXCL10 but also BM-MSC and tumour-MSC supernatants were able to significantly attract both $\mathrm{T}$-cell subpopulations.

The frequency of CD90-positive stromal cells in HNSCC directly correlates with tumour size. To investigate the possible role of tumour-MSCs in the growth of HNSCC tumours, we took advantage of the data regarding the frequency of CD90 + cells in tumour specimens; the mesenchymal nature of these cells 

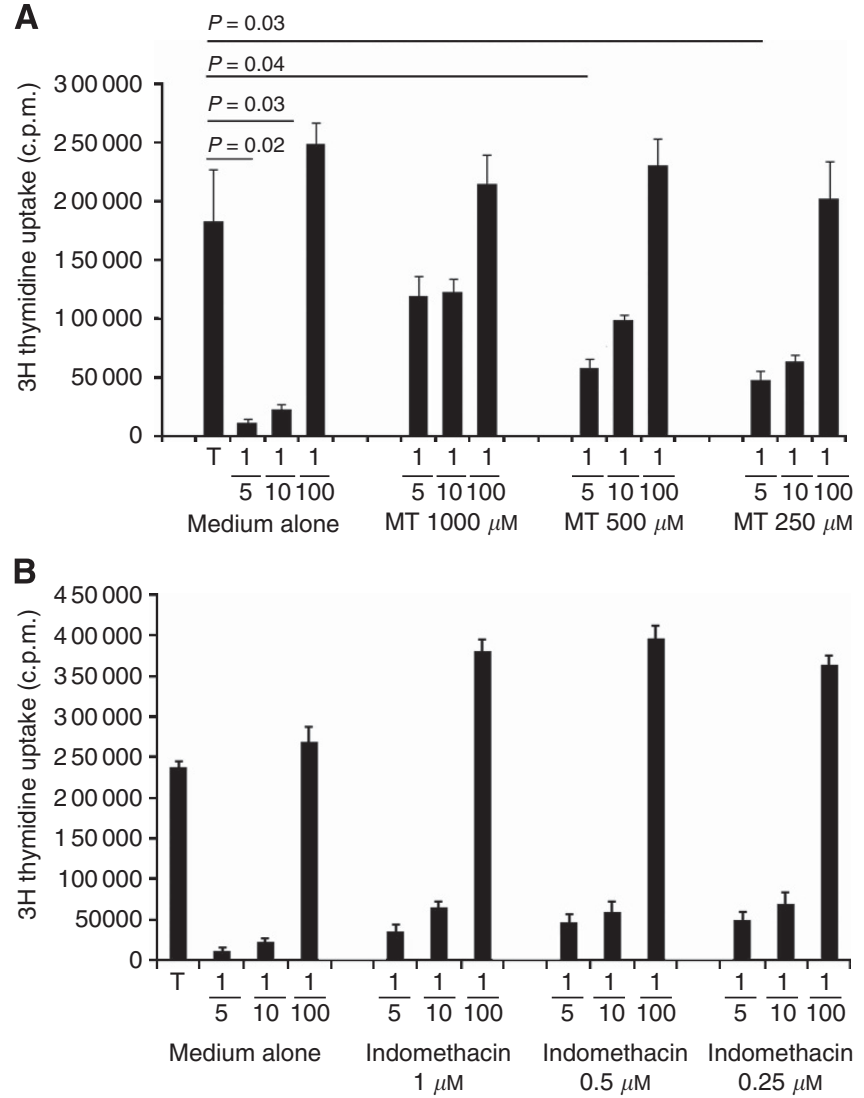

Figure 4. Indoelamine 2,3 dioxygenase (IDO) activity is on the basis of tumour-MSCs immunoregulatory activity. (A) Cell proliferation of polyclonally stimulated CD4 + T cells was assessed as previously indicated in the absence or in the presence of tumour-MSCs with or without the IDO1 inhibitor methyl-L-triptophane in scalar doses. Histograms represent mean values \pm s.e. of four different experiments. $P$-values are evaluated vs T cells alone. (B) Analogous experiments were conducted in the absence or in the presence of the COX inhibitor indomethacin in scalar concentration. Histograms represent mean values \pm s.e. of four different experiments; $P$-value was calculated vs T cells alone and resulted $<0.01$ at MSC/T-cell ratio $1 / 5$ and 1/10 in the control condition (medium alone) and also in the presence of the different concentrations of indomethacin.

was confirmed by flow cytometric analysis by evaluating the co-expression of CD29, CD73, and CD105, in the absence of CD133, CD45, CD31, CD14, and HEA (data not shown). In particular, the frequency of CD90 + cells measured in single-cell suspension freshly derived from tumour specimens, was correlated with the dimension of neoplasm, as measured by computed tomography: longitudinal $\times$ lateral $\times$ transversal diameter $(\mathrm{cm}) \times \pi / 6$ (Dethlefsen et al, 1968). As shown in Figure 6, the frequency of $\mathrm{CD} 90+$ cells directly and significantly correlated with tumour volume. Interestingly the frequency of $\mathrm{CD} 90+$ cells inversely correlated with the frequency of tumour-infiltrating leukocytes (CD45 + cells). Finally a positive trend in the correlation between $\mathrm{CD} 90+$ cells and endothelial CD31 + cells was observed, but, in this case, the statistical analysis did not give a significant result, probably because of the lower number of subjects evaluated for CD31.

\section{DISCUSSION}

Mesenchymal stem cells are essential components of tumour stromal cells, and have a pivotal role in tumour microenvironment,

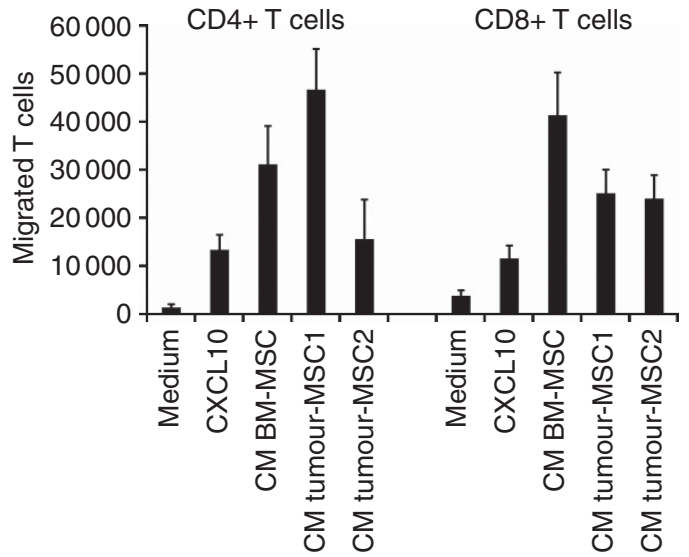

Figure 5. Tumour-MSC actively attract CD4 + and CD8 + T cells. In vitro chemotaxis of CD4 + or CD8 $+\mathrm{T}$ cells was evaluated in transwell chambers in the presence of normal culture medium (negative control), in the presence of CXCL10 (positive control), or in the presence of medium conditioned by tumour-MSC derived from two different patients (tumour-MSC1 and 2). As further control, the conditioned medium obtained from BM-MSC also was evaluated. Histograms represent the mean values \pm s.e. of triplicates of two separated experiments.

by modulating tumour growth and development. These cells are able to become tumour-associated fibroblasts (TAFs), which contribute to fibrovascular network expansion and tumour progression (Mishra et al, 2008; Spaeth et al, 2009). Mesenchymal stem cells are also capable of differentiating into pericytes and mural cells around tumour blood vessels, thus contributing to the formation of tumoral vasculature (Rajantie et al, 2004). Mesenchymal stem cells are generally believed to reach the tumour from the bone marrow (Horwitz et al, 2005), in as much as a strong evidence demonstrates that MSCs home to injury sites in various pathological conditions, including inflammation, tissue repair, and neoplasms (Natsu et al, 2004; Rojas et al, 2005; Hall et al, 2007). During progression and development of tumours, MSCs can be recruited in large numbers to the tumour site. On the other hand, it is well known that BM-MSCs exert immunosuppressive activity on various cells of the immune system (Hu et al, 2013).

In the present study, we hypothesised that MSC or MSC-like cells present in HNSCC exhibit immunoregulatory activities, similar to their bone marrow counterpart, favouring tumour escape, growth, and progression of disease. To assess this issue, we evaluated, by flow cytometric analysis, the relative proportions of cells belonging to the stromal/mesenchymal lineage $(\mathrm{CD} 90+$, $\mathrm{CD} 29+, \mathrm{CD} 105+, \mathrm{CD} 73+, \mathrm{CD} 31-, \mathrm{CD} 45-, \mathrm{CD} 133-$, cells), cells of endothelial origin (CD31 + elements), of epithelial origins (HEA + elements), and leukocytes (CD45 + cells). CD90+ stromal cells were significantly enriched in fresh samples of tumour tissue compared with healthy tissue derived from the aerodigestive tract of the same patients, whereas no significant differences were noticed for the other cell markers. Moreover, we demonstrated that it was possible to derive from HNSCC, homogeneous cultures of cell resembling classic BM-MSC in terms of morphology, immune-phenotype, and differentiation potential. In particular, stromal cells isolated from tumour samples, showed a fibroblast-like shape when evaluated by direct microscopy and the same immunophenotype pattern of BM-MSC as evaluated by flow cytometry $(\mathrm{CD} 44+, \mathrm{CD} 105+, \mathrm{CD} 73+, \mathrm{CD} 90+, \mathrm{CD} 29+$, $\mathrm{CD} 31-, \mathrm{CD} 45-, \mathrm{CD} 14-, \mathrm{CD} 34-, \mathrm{HEA}-)$. The results demonstrated that adherent cells isolated by tumoral specimens were homogeneously characterised by the same phenotype of BMMSCs obtained from healthy donors. To evaluate the functional capability of tumour-MSCs to differentiate towards specific 

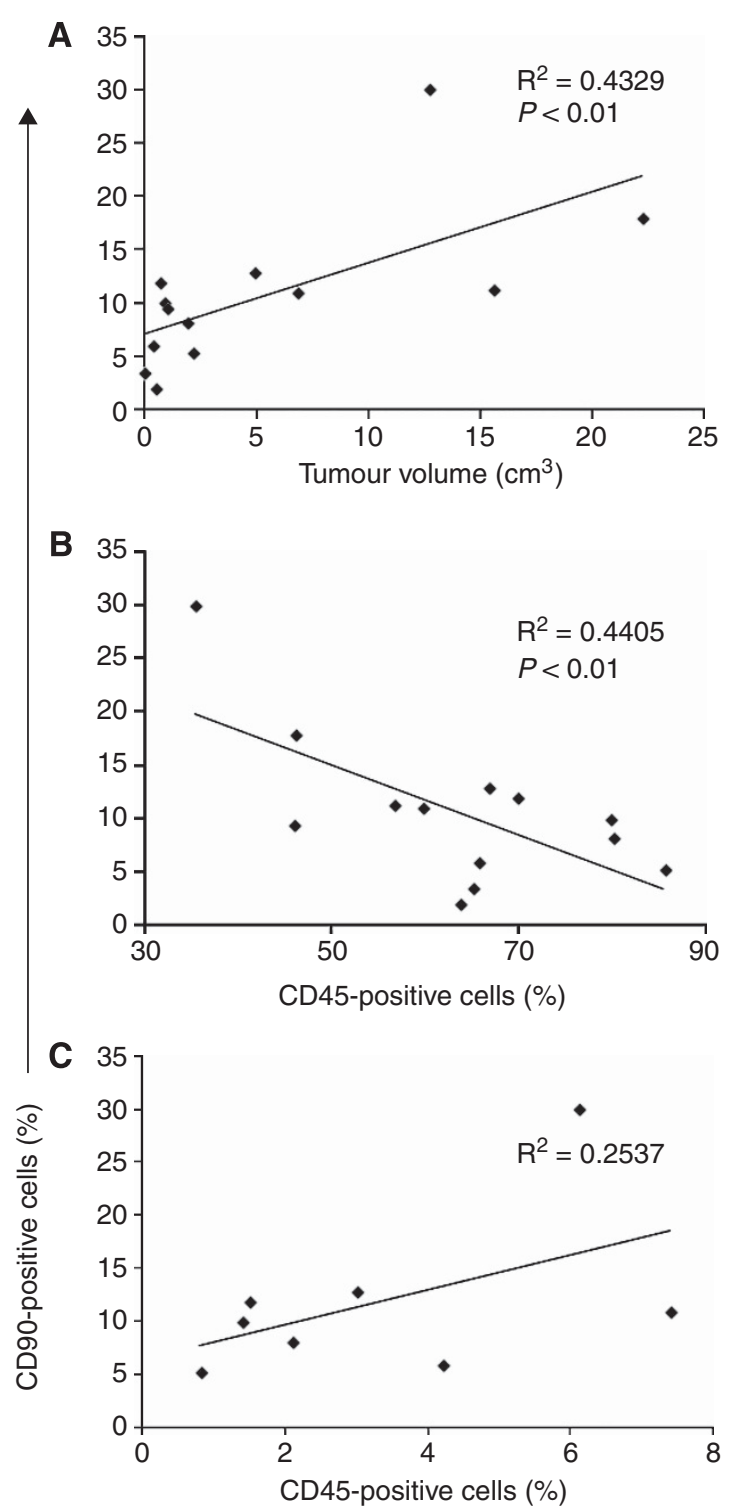

Figure 6. Frequency of CD90-positive cells in HNSCC directly correlates with tumour volume and inversely with leukocyte infiltrate. (A) The frequency of CD90 + cells present at level of HNSCC fresh samples, as assessed by flow cytometry on single-cell suspensions, was correlated with tumour size (longitudinal $\times$ lateral $\times$ transversal diameter $(\mathrm{cm}) \times 0.52), n=13$. (B) The frequency of CD90 + cells determined as previously described, was correlated with the frequency of tumour-infiltrating leukocyte $(C D 45+) n=13$. (C) The frequency of CD90 + cells was correlated with the frequency of endothelial cells $\left(\right.$ CD $45-$ CD31 + cells) $n=8 \cdot R^{2}$ and $P$-values are indicated in each panel.

stromal cell lineages, we cultured them in the presence of appropriate differentiating media for osteoblast or adipoblast differentiation. This functional capability allows us to conclude that these tumour-derived cells are MSCs and not fibroblasts, and indeed it is not possible to distinguish MSCs from fibroblasts on the basis of the immunophenotype alone. After adequate cell culturing, we were able to demonstrate both osteogenic and adipogenic cell differentiation either in terms of immunohistochemistry or expression of specific mRNAs, as measured by realtime quantitative RT-PCR. Thus, we concluded that tumour-MSCs share morphologic, immunophenotypic, and differentiation features with BM-MSCs.

As a second step, we evaluated the in vitro immunoregulatory properties of tumour-MSCs. To this end, we co-cultured scalar numbers of tumour-MSCs with anti-CD3 plus anti-CD28 - or MLR-stimulated CD4 + or CD8 + T cells, and then we measured the proliferative activity of lymphocytes by $3 \mathrm{H}$ thymidine uptake after 5 days of culture. The results of these experiments demonstrated that tumour-MSCs consistently and significantly inhibited the in vitro proliferation of CD4 + and of CD8 + T cells, at the higher MSC/lymphocytes ratios (1/5 and 1/10), in the same manner as control BM-MSCs. Moreover, we demonstrated that tumour-MSCs share the main molecular mechanisms of immune suppression with BM-MSCs, namely the enzymatic activity of IDO1. As known, this enzyme is induced in human MSCs by IFN- $\gamma$ produced by $\mathrm{T}$ or by NK cells, and is responsible for the catabolism of the essential amino acid tryptophan, and for the generation of the toxic compounds kynurenines; these latter are inhibitory for T-cell proliferation and cytokine production and also responsible for apoptosis induction. In particular, we showed that addition in culture of the IDO inhibitor 6-methyl-L-triptophane abrogated the tumour-MSC inhibitory effect on T-cell proliferation, whereas the addition of the COX antagonist indomethacin that have been reported by some researchers to have inhibitory effects on MSC immunoregulation, had poor effect on BM- and on tumour-MSCs, at least in our hands. Interestingly tumour-MSCs resulted were able to attract $\mathrm{CD} 4+$ and $\mathrm{CD} 8+\mathrm{T}$ cells in in vitro chemotactic assays, supporting the idea that tumour-MSC are able to actively attract $\mathrm{T}$ lymphocytes and then suppress them in terms of cell proliferation and cytokine production. These data are consistent with a recent publication where it has been demonstrated that MSC derived from different tumours are able to attract in vitro peripheral blood mononuclear cells (Al-toub et al, 2013).

Taken together, these data demonstrate that the in vitro immunoregulatory activity of tumour-MSC is quantitatively and qualitatively comparable with that of BM-MSCs. On this basis, we hypothesised that tumour-MSC also could possess an immunoregulatory activity in vivo, as already demonstrated for BM-MSCs (Bartholomew et al, 2002; Le Blanc et al, 2004; Baron et al, 2010). To verify this hypothesis, we evaluated the correlation between the frequency of tumour-MSC present in neoplasm specimens and the tumour size. We could appreciate a direct and significant correlation between these two parameters, suggesting a favouring role of tumour-MSC for neoplasm growth. More interestingly, we observed an inverse and significant correlation between tumourMSCs and the frequencies of leukocytes infiltrating the tumour, thus suggesting that tumour-MSCs could exert immunoregulatory activity also in vivo, as already shown in in vitro models, as well as in mice and in humans with regard to BM-MSC. Our data are in agreement with the work by Ling et al (2014), that demonstrates the ability of mice MSC, transfected with human IDO, to strongly inhibit in vitro cell proliferation of both $\mathrm{CD} 4+$ and $\mathrm{CD} 8+$ $\mathrm{T}$ lymphocytes. Moreover the positive correlation between CD90 + cells and tumour size is in keeping with a recent publication by Kansy et al (2014), where the authors confirm the presence of MSCs in HNSCC, and find that MSCs in vitro can establish a direct crosstalk with tumoral cells resulting in MSC activation, cytokines production, and subsequent tumoral cell growth.

In conclusion, our study demonstrates that in head neck tumours, the MSC cell population is enriched when compared with control healthy tissue, and shares with conventional BM-MSCs both immunophenotype and differentiation potential. Thus, these cells possess the potential to work as the stromal progenitors at tumoral level, implicated in the generation of the different cell type of tumoral connective tissue; in accordance with this concept, we observed a positive trend, even if not significant, between $\mathrm{CD} 90+$ cells and CD31 + CD45 - (endothelial) cells. Interestingly, tumour-MSCs exhibit evidence for immunosuppressive activity in in vitro models, being able to abrogate cell proliferation and cytokine production by CD $4+$ and CD $8+T$ cells. Notably, the molecular mechanism on the basis of this immunoregulatory 
activity is mainly related to the IDO activity, as already demonstrated for conventional human BM-MSCs, whose immunosuppressive activity in vivo is well documented. These data together with the observation that the frequency of tumour-MSCs directly correlates with tumour size and inversely correlates with the numbers of tumour-infiltrating leucocytes, let us to hypothesize that tumour-MSCs may favour tumour growth, either directly or indirectly inhibiting the immune response. However, these data need to be confirmed on a bigger cohort of patients and the correlation between the frequency of tumour-MSCs and the clinical history of the disease need to be monitored for an adequate followup period.

\section{ACKNOWLEDGEMENTS}

We thank Daniela Massi for immunohistochemistry. Department of Human Pathology and Oncology, University of Florence, Italy. This study was supported by grants from Ministero dell'Istruzione, dell'Universita'e della Ricerca, the Italian Ministry of Health, Associazione Italiana Ricerca sul Cancro (AIRC), and Ente Cassa Risparmio di Firenze.

\section{CONFLICT OF INTEREST}

The authors declare no competing financial interests.

\section{REFERENCES}

Al-toub M, Almusa A, Almajed M, Al-Nbaheen M, Kassem M, Aldahmash A, Alajez NM (2013) Pleiotropic effects of cancer cells' secreted factors on human stromal (mesenchymal) stem cells. Stem Cell Res Ther 4: 114.

Annunziato F, Romagnani S (2010) The transient nature of the Th17 phenotype. Eur J Immunol 40: 3312-3316.

Baker KS, DeFor TE, Burns LJ, Ramsay NK, Neglia JP, Robison LL (2003) New malignancies after blood or marrow stem-cell transplantation in children and adults: incidence and risk factors. J Clin Oncol 21: 1352-1358.

Baron F, Lechanteur C, Willems E, Bruck F, Baudoux E, Seidel L, Vanbellinghen JF, Hafraoui K, Lejeune M, Gothot A, Fillet G, Beguin Y (2010) Cotransplantation of mesenchymal stem cells might prevent death from graft-versus-host disease (GVHD) without abrogating graftversus-tumor effects after HLA-mismatched allogeneic transplantation following nonmyeloablative conditioning. Biol Blood Marrow Transplant 16: $838-847$.

Bartholomew A, Sturgeon C, Siatskas M, Ferrer K, McIntosh K, Patil S, Hardy W, Devine S, Ucker D, Deans R, Moseley A, Hoffman R (2002) Mesenchymal stem cells suppress lymphocyte proliferation in vitro and prolong skin graft survival in vivo. Exp Hematol 30: 42-48.

Bergfeld SA, DeClerck YA (2010) Bone marrow-derived mesenchymal stem cells and the tumor microenvironment. Cancer Metastasis Rev 29: 249-261.

Bieback K, Kluter H (2007) Mesenchymal stromal cells from umbilical cord blood. Curr Stem Cell Res Ther 2: 310-323.

Bruno S, Bussolati B, Grange C, Collino F, di Cantogno LV, Herrera MB, Biancone L, Tetta C, Segoloni G, Camussi G (2009) Isolation and characterization of resident mesenchymal stem cells in human glomeruli. Stem Cells Dev 18: 867-879.

Cosmi L, De Palma R, Santarlasci V, Maggi L, Capone M, Frosali F, Rodolico G, Querci V, Abbate G, Angeli R, Berrino L, Fambrini M, Caproni M, Tonelli F, Lazzeri E, Parronchi P, Liotta F, Maggi E, Romagnani S, Annunziato F (2008) Human interleukin-17 producing cells originate from a CD161+ CD4 + T-cell precursor. J Exp Med 205: 1903-1916.

De Boeck A, Narine K, De Neve W, Mareel M, Bracke M, De Wever O (2010) Resident and bonemarrow-derived mesenchymal stem cells in head and neck squamous cell carcinoma. Oral Oncol 46: 336-342.

Dethlefsen LA, Prewitt JM, Mendelsohn ML (1968) Analysis of tumor growth curves. J Natl Cancer Inst 40: 389-405.
De Wever O, Demetter P, Mareel M, Bracke M (2008) Stromal myofibroblasts are drivers of invasive cancer growth. Int J Cancer 123: 2229-2238.

Dominici M, Le Blanc K, Mueller I, Slaper-Cortenbach I, Marini F, Krause D, Deans R, Keating A, Dj Prockop, Horwitz E (2006) Minimal criteria for defining multipotent mesenchymal stromal cells. The International Society for Cellular Therapy position statement. Cytotherapy 8: 315-317.

Edge S, Byrd DR, Compton CC, Fritz AG, Greene FL, Trotti A (2010) AJCC Cancer Staging Manual 7th edn. XV, 649 p.

Finn OJ (2012) Understanding the function and dysfunction of the immune system in cancer. Ann Oncol 23(Suppl 8): viii6-viii9.

Flynn A, Barry F, O'Brien T (2007) UC blood-derived mesenchymal stromal cells: an overview. Cytotherapy 9: 717-726.

Forastiere A, Koch W, Trotti A, Sidransky D (2001) Head and neck cancer. $N$ Engl J Med 345: 1890-1900.

Gucciardo L, Lories R, Ochsenbein-Kölble N, Done' E, Zwijsen A, Deprest J (2009) Fetal mesenchymal stem cells: isolation, properties and potential use in perinatology and regenerative medicine. BJOG 116: $166-172$.

Hall B, Andreeff M, Marini F (2007) The participation of mesenchymal stem cells in tumor stroma formation and their application as targeted-gene delivery vehicles. Handb Exp Pharmacol 180: 263-283.

Harris JP, Penn I (1981) Immunosuppression and the development of malignancies of the upper airway and related structures. Laryngoscope 91: 520-528.

Horwitz EM, Le Blanc K, Dominici M, Mueller I, Slaper-Cortenbach I, Marini FC, Deans RJ, Krause DS, Keating A (2005) Clarification of the nomenclature for MSC: The International Society for Cellular Therapy position statement. Cytotherapy 7: 393-395.

Hu J, Zhou Z, Shi S, Zhu X, Wang X, Zhang W, Hu S, Qian H, Xu W (2013) Mesenchymal stem-like cells isolated from human esophageal carcinoma and adjacent non-cancerous tissues. Oncol Lett 5: 179-184.

In't Anker PS, Scherjon SA, Kleijburg-van der Keur C, Noort WA, Claas FH, Willemze R, Fibbe WE, Kanhai HH (2003) Amniotic fluid as a novel source of mesenchymal stem cells for therapeutic transplantation. Blood 102: 1548-1549.

Kansy BA, Dißmann PA, Hemeda H, Bruderek K, Westerkamp AM, Jagalski V, Schuler P, Kansy K, Lang S, Dumitru CA, Brandau S (2014) The bidirectional tumor-mesenchymal stromal cell interaction promotes the progression of head and neck cancer. Stem Cell Res Ther 5: 95.

King GN, Healy CM, Glover MT, Kwan JT, Williams DM, Leigh IM, Worthington HV, Thornhill MH (1995) Increased prevalence of dysplastic and malignant lip lesions in renal-transplant recipients. N Engl J Med 332: 1052-1057.

Krampera M, Cosmi L, Angeli R, Pasini A, Liotta F, Andreini A, Santarlasci V, Mazzinghi B, Pizzolo G, Vinante F, Romagnani P, Maggi E, Romagnani S, Annunziato F (2006) Role for IFN- $\gamma$ in the immunomodulatory activity of human bone marrow mesenchymal stem cells. Stem Cells 24(2): 386-398.

Le Blanc K, Rasmusson I, Sundberg B, Götherström C, Hassan M, Uzunel M, Ringdén O (2004) Treatment of severe graft-versus-host disease with third party haploidentical mesenchymal stem cells. Lancet 363: 1439-1441.

Ling W, Zhang J, Yuan Z, Ren G, Zhang L, Chen X, Rabson AB, Roberts AI, Wang Y, Shi Y (2014) Mesenchymal stem cells use IDO to regulate immunity in tumor microenvironment. Cancer Res 74: 1576-1587.

Lin TM, Chang HW, Wang KH, Kao AP, Chang CC, Wen CH, Lai CS, Lin SD (2007) Isolation and identification of mesenchymal stem cells from human lipoma tissue. Biochem Biophys Res Commun 361: 883-889.

Liotta F, Angeli R, Cosmi L, Fili L, Manuelli C, Frosali F, Mazzinghi B, Maggi L, Pasini A, Lisi V, Santarlasci V, Consoloni L, Angelotti ML, Romagnani P, Parronchi P, Krampera M, Maggi E, Romagnani S, Annunziato F (2008) TLR3 and TLR4 are expressed by human bone marrow-derived mesenchymal stem cells and can inhibit their T-cell modulatory activity by impairing Notch signalling. Stem Cells 26: 279-289.

Mishra PJ, Mishra PJ, Humeniuk R, Medina DJ, Alexe G, Mesirov JP, Ganesan S, Glod JW, Banerjee D (2008) Carcinoma-associated fibroblastlike differentiation of human mesenchymal stem cells. Cancer Res $\mathbf{6 8}$ : 4331-4339.

Mitrano TI, Grob MS, Carrión F, Nova-Lamperti E, Luz PA, Fierro FS, Quintero A, Chaparro A, Sanz A (2010) Culture and characterization of mesenchymal stem cells from human gingival tissue. J Periodontol 81: 917-925.

Murphy KM, Stockinger B (2010) Effector T cell plasticity: flexibility in the face of changing circumstances. Nat Immunol 11: 674-680. 
Nakahara H, Dennis JE, Bruder SP, Haynesworth SE, Lennon DP, Caplan AI (1991) In vitro differentiation of bone and hypertrophic cartilage from periosteal-derived cells. Exp Cell Res 195: 492-503.

Natsu K, Ochi M, Mochizuki Y, Hachisuka H, Yanada S, Yasunaga Y (2004) Allogeneic bone marrow-derived mesenchymal stromal cells promote the regeneration of injured skeletal muscle without differentiation into myofi bers. Tissue Eng 10: 1093-1112.

Rajantie I, Ilmonen M, Alminaite A, Ozerdem U, Alitalo K, Salven P (2004) Adult bone marrow- derived cells recruited during angiogenesis comprise precursors for periendothelial vascular mural cells. Blood 104: 2084-2086.

Rojas M, Xu J, Woods CR, Mora AL, Spears W, Roman J, Brigham KL (2005) Bone marrow-derived mesenchymal stem cells in repair of the injured lung. Am J Respir Cell Mol Biol 33: 145-152.

Schüring AN, Schulte N, Kelsch R, Röpke A, Kiesel L, Götte M (2011) Characterization of endometrial mesenchymal stem-like cells obtained by endometrial biopsy during routine diagnostics. Fertil Steril 95: 423-426.

Spaeth EL, Dembinski JL, Sasser AK, Watson K, Klopp A, Hall B, Andreeff M, Marini F (2009) Mesenchymal stem cell transition to tumor-associated fibroblasts contributes to fibrovascular network expansion and tumor progression. PLoS One 4(4): e4992.
Sturgis EM, Cinciripini PM (2007) Trends in head and neck cancer incidence in relation to smoking prevalence: an emerging epidemic of human papillomavirus-associated cancers? Cancer 110: 1429-1435.

Sun X, Cai H, Qian H, Zhu W, Yan Y, Xu H, Xu W (2011) Mesenchymal stem cells isolated from human uterine cervix cancer tissues. Cell Biol Int 35: $119-123$.

Xu X, Zhang X, Wang S, Qian H, Zhu W, Cao H, Wang M, Chen Y, Xu W (2011) Isolation and comparison of mesenchymal stem-like cells from human gastric cancer and adjacent non-cancerous tissues. J Cancer Res Clin Oncol 137: 495-504.

Zuk PA, Zhu M, Ashiian P, De Ugarte DA, Huang JI, Mizuno H, Alfonso ZC, Fraser JK, Benhaim P, Hedrick MH (2002) Human adipose tissue is a source of multipotent stem cells. Mol Biol Cell 13: 4279-4295.

This work is published under the standard license to publish agreement. After 12 months the work will become freely available and the license terms will switch to a Creative Commons AttributionNonCommercial-Share Alike 4.0 Unported License. 